\title{
Reference values for the incremental shuttle walk test in healthy subjects: from the walk distance to physiological responses ${ }^{*, * * *}$
}

\author{
Valores de referência para o teste de caminhada com carga progressiva \\ em indivíduos saudáveis: da distância percorrida às respostas fisiológicas
}

\author{
Victor Zuniga Dourado, Ricardo Luís Fernandes Guerra, Suzana Erico Tanni, \\ Letícia Cláudia de Oliveira Antunes, Irma Godoy
}

\begin{abstract}
Objective: To determine reference values for incremental shuttle walk distance (ISWD) and peak physiological responses during the incremental shuttle walk test (ISWT), as well as to develop a series of predictive equations for those variables in healthy adults. Methods: We evaluated 103 healthy participants $\geq 40$ years of age (54 women and 49 men). We fitted each participant with a gas analysis system for use during the 1SWT. 0xygen consumption ( $\mathrm{VO}_{2}$ ), carbon dioxide production, minute ventilation, heart rate (HR), ISWD, and maximal walking velocity (MWV) were obtained as primary outcomes. We also assessed hand grip strength (HGS) and lean body mass (LBM). Results: The regression analysis models, including physiological variables, ISWD, and MWV (adjusted for age, body mass, height, and sex), produced $\mathrm{R}^{2}$ values ranging from 0.40 to 0.65 (for $\mathrm{HR}$ and peak $\mathrm{VO}_{2}$, respectively). Using the models including LBM or HGS, we obtained no significant increase in the $\mathrm{R}^{2}$ values for predicting peak $\mathrm{VO}_{2}$, although the use of those models did result in slight increases in the $\mathrm{R}^{2}$ values for ISWD and MWV (of 8\% and 12\%, respectively). The variables ISWD, MWV, and ISWD $\times$ body mass, respectively, explained 76.7\%, 73.3\%, and 81.2\% of peak $\mathrm{VO}_{2}$ variability. Conclusions: Our results provide reference values for ISWD and physiological responses to the 1SWT, which can be properly estimated by determining simple demographic and anthropometric characteristics in healthy adults $\geq 40$ years of age. The 1SWT could be used in assessing physical fitness in the general adult population and in designing individualized walking programs.
\end{abstract}

Keywords: Reference values; Pulmonary gas exchange; Walking; Exercise test.

\section{Resumo}

Objetivo: Determinar valores de referência para a distância caminhada (DC) e para respostas fisiológicas durante o teste de caminhada com carga progressiva (TCCP) e desenvolver equações preditivas para essas variáveis em adultos saudáveis. Métodos: Foram avaliados 103 participantes saudáveis com idade $\geq 40$ anos (54 mulheres e 49 homens). Os participantes usaram um sistema de análise de gases durante o TCCP. Consumo de oxigênio $\left(\mathrm{VO}_{2}\right)$, liberação de gás carbônico, ventilação minuto, frequência cardíaca $(\mathrm{FC})$, DC e velocidade máxima da caminhada (VMC) foram obtidos como desfechos primários. Avaliamos também a força de preensão manual (FPM) e a massa magra corporal (MMC). Resultados: Os modelos de regressão utilizando variáveis fisiológicas, DC e VMC ajustados por idade, massa corporal, estatura e sexo apresentaram valores de $R^{2}$ entre 0,40 e 0,65 (para FC e pico de $\mathrm{VO}_{2}$, respectivamente). Os modelos incluindo MMC e FPM não aumentaram consideravelmente os valores de $\mathrm{R}^{2}$ na previsão do pico de $\mathrm{VO}_{2}$, embora esses modelos tenham aumentado discretamente os valores do $\mathrm{R}^{2}$ para DC e VMC (8\% e 12\%, respectivamente). As variáveis DC, VMC e DC $\times$ massa corporal, respectivamente, explicaram 76,7\%, 73,3\% e 81,2\% da variabilidade do pico de $\mathrm{VO}_{2}$. Conclusões: Nossos resultados originaram valores de referência para a DC e respostas fisiológicas ao TCCP, que podem ser estimados adequadamente por características demográficas e antropométricas simples em adultos saudáveis com idade $\geq 40$ anos. 0 TCCP poderia ser utilizado na avaliação da capacidade física na população geral de adultos e no desenvolvimento de programas de caminhada individualizados.

Descritores: Valores de referência; Troca gasosa pulmonar; Caminhada; Teste de esforço.

*Study carried out at the Universidade Federal de São Paulo - UNIFESP, Federal University of São Paulo - Baixada Santista Campus, Santos, Brazil.

Financial support: This study received financial support from the Fundação de Amparo à Pesquisa do Estado de São Paulo (FAPESP, São Paulo Research Foundation).

Correspondence to: Victor Z. Dourado. Avenida Ana Costa, 95, CEP 11060-001, Santos, SP, Brasil.

Tel./Fax: 5513 3261-3324.E-mail: vzdourado@yahoo.com.br or victor.dourado@unifesp.br

Submitted: 13 September 2012. Accepted, after review: 15 January 2013.

**A versão completa em português deste artigo está disponível em www.jornaldepneumologia.com.br 


\section{Introduction}

The incremental shuttle walk test (ISWT) was developed in order to assess the functional exercise capacity of patients with COPD. ${ }^{(1)}$ The test subject walks back and forth along a 10-m flat course, with progressive increases in pace imposed by audio signals, until no longer able to maintain the pace. The incremental character of the ISWT yields physiological responses closer to those observed in cardiopulmonary exercise testing (CPET). ${ }^{(2)}$ Some authors argue that, as an externally paced walk test, the ISWT is more reproducible and yields greater physiological responses in comparison with self-paced walk tests. ${ }^{(3)}$ One of the greatest advantages of the ISWT is its simplicity. The incremental shuttle walk distance (ISWD) is generally used as an index of cardiorespiratory fitness and has been suggested as a prognostic indicator in patients with chronic disease. ${ }^{(4)}$

Because of its simplicity and low cost, walking is the most popular exercise for middle-aged and older adults. In healthy subjects, the heart rate variability threshold was reported to be a valid tool for estimating the ventilatory threshold during the 1SWT. ${ }^{(5)}$ The ISWT has also proven useful for quantifying the benefits of a walking program designed for healthy individuals. ${ }^{(6)}$ Studies evaluating the 1SWT in healthy subjects have shown that the ISWT is valid and responsive. Despite the widespread use of the ISWT in clinical settings, few studies have assessed reference values and physiological responses to the test. Recently, the ISWD has been investigated in healthy subjects, and regression equations have been developed, allowing a better interpretation of walking performance. ${ }^{(7-9)}$ Two such studies enrolled participants with comorbidities, ${ }^{(7,9)}$ whereas another included only healthy individuals. (8) However, to our knowledge, there have been no studies evaluating physiological responses to the ISWT in healthy subjects in other than a superficial manner.

Although the operational simplicity of walk tests is recognized as their most important quality, the ISWT has been evaluated with the aid of sophisticated telemetric gas analysis systems in order to evaluate physiological responses, especially in patients with cardiorespiratory diseases. ${ }^{(2,10)}$ In such patients, the peak oxygen consumption $\left(\mathrm{VO}_{2}\right)$ achieved on the 1SWT exhibits a strong correlation with that achieved in CPET performed on a treadmill or on a cycle ergometer. ${ }^{(10,11)}$ Therefore, the 1SWT appears to induce a maximum exercise response that is appropriate for assessing functional capacity. ${ }^{(12)}$ Elucidation of such physiological responses might be useful for assessing exercise capacity and for designing walking programs for middle-aged and older adults. In addition, reference values, especially for $\mathrm{VO}_{2}$ and $1 \mathrm{SWD}$, might provide an easy way to assess the functional exercise capacity in patients with chronic diseases.

In this study, our primary objective was to determine reference values for ISWD and peak physiological responses during the ISWT, developing a series of simple predictive equations for those variables in healthy middle-aged adults and in healthy older adults. We also assessed the influence that body composition and muscle strength have on the main physiological variables obtained during the ISWT.

\section{Methods}

We conducted a cross-sectional study to evaluate the physiological responses to the ISWT in 103 healthy adults aged 40 years and older. The Research Ethics Committee of the Federal University of São Paulo, located in the city of São Paulo, Brazil, approved the study, and all participants provided written informed consent.

We recruited a convenience sample from among employees of the institution and residents of the surrounding community. The following individuals were ineligible for inclusion in the study: those with a body mass index $>35 \mathrm{~kg} / \mathrm{m}^{2}$; those who used a walking aid; those who exhibited abnormal post-bronchodilator spirometric results ${ }^{(13)}$; those who reported having cardiorespiratory, metabolic, neuromuscular, or musculoskeletal disease; and those who were current smokers.

Eligible participants underwent a series of evaluations over the course of two mornings, with a 7-day interval between the two. On day 1 , the participants completed a physical activity readiness questionnaire, a face-to-face interview based on the main cardiovascular risk factors, and a physical activity questionnaire in accordance with the American College of Sports Medicine recommendations ${ }^{(14)}$ so that we could exclude those involved in high-intensity exercise and sports. They also underwent spirometry, hand grip strength (HGS) assessment, and anthropometric and body composition measurements. Those 
who met the eligibility criteria returned on day 2 and underwent three 1SWTs, 20 min apart.

Body mass (in $\mathrm{kg}$ ) and height (in $\mathrm{m}$ ) were measured, and the body mass index (in $\mathrm{kg} / \mathrm{m}^{2}$ ) was calculated. Body composition was assessed using a portable scale with a tetrapolar bioelectrical impedance system (TBF-310GS; Tanita, Arlington Heights, IL, USA). ${ }^{(15)}$ Total body fat (TBF), total body water, and lean body mass (LBM) were assessed using regression equations. ${ }^{(16)}$ The LBM was also expressed as a percentage of the predicted value. ${ }^{(17)}$ Spirometry was performed using a handheld spirometer (Spiropalm; Cosmed, Pavona di Albano, 1taly) in accordance with the criteria established by the Brazilian Thoracic Association. (13) We measured $\mathrm{FEV}_{1}, \mathrm{FVC}$, and $\mathrm{FEV}_{1} / \mathrm{FVC}$ ratio. The HGS of the dominant side was assessed using a hydraulic dynamometer (HS5001; Carci, São Paulo, Brazil). ${ }^{(18)}$ Three measurements were performed at least $30 \mathrm{~s}$ apart. The highest value was selected for further analysis.

We conducted the 1SWTs in a 10-m corridor, increasing the pace by $0.17 \mathrm{~m} / \mathrm{s}$ every minute. ${ }^{(1)}$ Dyspnea and leg fatigue were quantified before and after each test with the Borg scale. Three 1SWTs were performed 20 min apart. The ISWD (in $\mathrm{m}$ ) and maximum walking velocity (MWV, in $\mathrm{m} / \mathrm{s}$ ) obtained on the third test were selected for further analysis. Because the 1SWT was developed to assess the functional exercise capacity of patients with lung disease, the original protocol consisted of 12 levels (total distance, 1,020 m). ${ }^{(1)}$ However, because we applied the test to healthy subjects, we extended it to 15 levels $(1,500 \mathrm{~m})$ in order to minimize the ceiling effect.

During the third 1SWT, expired gases were collected and assessed by a portable telemetric gas analysis system (K4b2; Cosmed; Pavona di Albano, Italy). The physiological responses were analyzed breath-by-breath, and the data were filtered every $15 \mathrm{~s}$. The following variables were focused at the peak of the ISWT: $\mathrm{VO}_{2}$, carbon dioxide production, $\mathrm{HR}$, and minute ventilation.

The data were evaluated descriptively and are presented as mean \pm standard deviation. Sex-related differences in the main physiological variables and the rate of perceived exertion were evaluated using Student's t-test or the MannWhitney test. Pearson's or Spearman's coefficients were used in order to assess bivariate correlations. To ensure that the ISWD obtained in the third test, carried out using the gas analysis system, was not inferior to that obtained in the second test, conducted without the equipment, we evaluated the intraclass correlation coefficient (ICC) with its 95\% $\mathrm{Cl}$ between those measures and compared their mean values using paired Student's t-test.

We calculated the sample size considering a minimum acceptable coefficient of correlation of 0.70 or a coefficient of determination $\left(\mathrm{R}^{2}\right)$ of 0.49. Assuming an alpha error of 0.05 and a beta error of 0.20 , a minimum of 12 observations for each variable included in the model would be sufficient. Therefore, 80 participants were necessary, and we were able to include up to 8 variables in each model. A series of multiple linear regression equations was developed using the main physiological responses as dependent variables. The models were first adjusted for age, body mass, height, and sex. This procedure was applied because these variables are easily obtained. For $\mathrm{VO}_{2}, \mathrm{MWV}$, and ISWD (the most important variables related to aerobic exercise capacity), the models were also adjusted for body composition variables and HGS. Regarding body composition, we chose LBM and TBF, which presented the strongest correlations in the previous bivariate analysis. In addition, we used linear regressions in alternative prediction models to determine whether peak $\mathrm{VO}_{2}$ correlated with ISWD, with ISWD $\times$ body mass, and with MWV. Multicollinearity was assessed before starting the regression procedures. The probability of an alpha error was set at 0.05 for all analyses. We performed the statistical analysis with the Statistical Package for the Social Sciences, version 15.0 (SPSS Inc., Chicago, IL, USA) and SigmaStat, version 3.1 (Systat Software lnc., San Jose, CA, USA).

\section{Results}

The sample comprised 103 participants (54 women and 49 men), and the mean age was $60 \pm 10$ years (Table 1). The participants were distributed within the following age brackets: 40-49 years ( 13 women and 12 men); 50-59 years (12 women and 11 men); 60-69 years (14 women and 14 men); and $\geq 70$ years ( 15 women and 12 men). There were no significant differences among the four age groups studied in terms of the proportions of women and men. Between the second and third ISWT, the ISWD reliability was excellent $(\mathrm{ICC}=0.973 ; 95 \% \mathrm{Cl}: 0.960-0.982)$ 
and there was no significant difference between the mean values ( $510 \pm 148 \mathrm{~m}$ vs. $519 \pm 161 \mathrm{~m})$.

The regression analysis models, using physiological variables, ISWD, and MWV as dependent variables and adjusted for age, body mass, height, and sex, showed $\mathrm{R}^{2}$ values ranging from 0.40 to 0.65 (for HR and peak $\mathrm{VO}_{2}$, respectively; Table 2). Applying the model

Table $\mathbf{1}$ - General characteristics of the study sample.

\begin{tabular}{|c|c|c|c|c|}
\hline \multirow{4}{*}{ Variable } & \multicolumn{4}{|c|}{ Sex } \\
\hline & \multirow{2}{*}{\multicolumn{2}{|c|}{$\begin{array}{c}\text { Female } \\
(n=54)\end{array}$}} & \multirow{2}{*}{\multicolumn{2}{|c|}{$\begin{array}{c}\text { Male } \\
(n=49)\end{array}$}} \\
\hline & & & & \\
\hline & Mean & SD & Mean & SD \\
\hline Age, year & 59 & 11 & 59 & 9 \\
\hline $\mathrm{BM}, \mathrm{kg}^{*}$ & 68 & 14 & 80 & 12 \\
\hline Height, m* & 1.57 & 0.07 & 1.71 & 0.07 \\
\hline $\mathrm{BMI}, \mathrm{kg} / \mathrm{m}^{2}$ & 27 & 5 & 27 & 3 \\
\hline TBF, $\mathrm{kg}^{*}$ & 31 & 10 & 20 & 7 \\
\hline TBF, \% of total $\mathrm{BM}^{*}$ & 35 & 6 & 25 & 5 \\
\hline $\mathrm{LBM}, \mathrm{kg}^{*}$ & 39 & 5 & 58 & 7 \\
\hline LBM, \% of total BM* & 64 & 6 & 74 & 5 \\
\hline LBM, \% of predicted & 102 & 7 & 103 & 5 \\
\hline $\mathrm{LBMl}, \mathrm{kg} / \mathrm{m}^{2 *}$ & 17 & 1 & 20 & 1 \\
\hline HGS, kgf* & 26 & 5 & 43 & 8 \\
\hline
\end{tabular}

BM: body mass; BMl: body mass index; TBF: total body fat; LBM: lean body mass; LBMI: lean body mass index; and HGS: handgrip strength. ${ }^{*} p<0.05$ (females vs. males). including LBM and that including HGS did not result in a significant increase in the $\mathrm{R}^{2}$ values for predicting peak $\mathrm{VO}_{2}$ (Table 2), although the use of those models did result in slight increases in the $\mathrm{R}^{2}$ values for ISWD and MWV (of 8\% and $12 \%$, respectively). We selected ISWD, MWV, and ISWD $\times$ body mass as the sole determinants of peak $\mathrm{VO}_{2}$. In three different models, those variables determined 76.7\%, 73.3\%, and 81.2\% of the peak $\mathrm{VO}_{2}$, respectively (Figure 1).

\section{Discussion}

This study investigated the major physiological responses to ISWT in healthy subjects. We derived a series of equations that can predict ISWD, as well as cardiovascular, ventilatory, and metabolic responses during the 1SWT. Age and sex had significant influences on those variables. However, after adjusting for sex and age, we found that MWV and ISWD were the main determinants of peak $\mathrm{VO}_{2}$, regardless of body composition and peripheral muscle strength.

The main finding of this study was the considerable influence that MWV and ISWD had on the peak $\mathrm{VO}_{2}$ obtained on the ISWT. The correlations between peak $\mathrm{VO}_{2}$ and ISWD, between peak $\mathrm{VO}_{2}$ and $\mathrm{MWV}$, and between peak $\mathrm{VO}_{2}$ and

Table 2 - Linear prediction equations, adjusted for age, body mass, height, sex, body composition, and muscle function, for peak physiological responses, total distance walked, and maximum walking velocity related to the incremental shuttle-walk test.

\begin{tabular}{|c|c|c|c|c|c|c|c|c|c|c|c|c|}
\hline \multirow[b]{2}{*}{ Variable } & \multirow[b]{2}{*}{ Model $^{\mathrm{a}}$} & \multicolumn{2}{|c|}{ Constant } & \multirow{2}{*}{$\begin{array}{l}\text { Age, } \\
\text { years }\end{array}$} & \multirow{2}{*}{$\begin{array}{c}\text { Body } \\
\text { mass, } \\
\text { kg }\end{array}$} & \multirow{2}{*}{$\begin{array}{l}\text { Height, } \\
\text { m }\end{array}$} & \multirow[b]{2}{*}{ Sex ${ }^{c}$} & \multirow{2}{*}{$\begin{array}{l}\text { HGS, } \\
\text { kgf }\end{array}$} & \multirow{2}{*}{$\begin{array}{l}\mathrm{LBM}, \\
\mathrm{kg}\end{array}$} & \multirow{2}{*}{$\begin{array}{l}\text { TBF, } \\
\%\end{array}$} & \multirow[b]{2}{*}{$\mathrm{R}^{2}$} & \multirow[b]{2}{*}{ Sy.x } \\
\hline & & Mean & LLN $^{\mathrm{b}}$ & & & & & & & & & \\
\hline $\mathrm{V}_{\mathrm{E}}, \mathrm{L} / \mathrm{min}$ & A & -43.7 & -67.2 & $-0.5^{*}$ & 0.1 & $69.2^{*}$ & $13.0^{*}$ & - & - & - & 0.54 & 14.3 \\
\hline HR, bpm & $A$ & 146.2 & 117.9 & $-1.1^{*}$ & $-0.4^{*}$ & $55.5^{*}$ & -2.1 & - & - & - & 0.40 & 17.2 \\
\hline $\mathrm{VCO}_{2}, \mathrm{~mL} / \mathrm{min}$ & A & 137.6 & -493.2 & $-22.5^{*}$ & $5.4^{*}$ & $1,317.9^{*}$ & $554.5^{*}$ & - & - & - & 0.63 & 383.5 \\
\hline \multirow{3}{*}{$\begin{array}{l}\text { Peak VO, } \mathrm{mL} / \\
\min \end{array}$} & A & 268.6 & -337.9 & $-21.1^{*}$ & $9.2^{*}$ & $1,101.1^{*}$ & $535.6^{*}$ & - & - & - & 0.65 & 368.1 \\
\hline & B & -134.1 & -750.6 & $-16.2^{*}$ & 8.8 & $938.7^{*}$ & 297.5 & $14.8^{*}$ & - & - & 0.65 & 374.9 \\
\hline & C & $-1,206.3$ & $-1,731.7$ & $-12.6^{*}$ & -21.0 & 883.3 & 207.8 & - & $56.0^{*}$ & 27.8 & 0.65 & 319.2 \\
\hline \multirow[t]{3}{*}{ ISWD, m } & A & 347.7 & 186.8 & $-7.2^{*}$ & $-3.0^{*}$ & $472.3^{*}$ & $137.2^{*}$ & - & - & - & 0.65 & 97.8 \\
\hline & B & 223.7 & 86.1 & $-5.8^{*}$ & $-3.2^{*}$ & 421.3 & 67.1 & $4.8^{*}$ & - & - & 0.73 & 83.6 \\
\hline & C & -54.6 & -198.4 & $-5.8^{*}$ & -4.3 & $666.0^{*}$ & 75.3 & - & 2.1 & 0.64 & 0.68 & 87.4 \\
\hline \multirow[t]{3}{*}{$\mathrm{MWV}, \mathrm{m} / \mathrm{s}$} & A & 1.59 & 1.32 & $-0.01^{*}$ & $-0.004^{*}$ & $0.70^{*}$ & $0.22^{*}$ & - & - & - & 0.60 & 0.17 \\
\hline & B & 0.89 & 0.66 & $-0.008^{*}$ & $-0.005^{*}$ & $0.92^{*}$ & 0.06 & $0.008^{*}$ & - & - & 0.72 & 0.14 \\
\hline & C & 0.55 & 0.32 & $-0.009^{*}$ & -0.007 & $1.23^{*}$ & 0.11 & - & 0.003 & 0.002 & 0.67 & 0.14 \\
\hline
\end{tabular}

LLN: lower limit of normal (calculated as $1.646 \times$ Sy.x); HGS: handgrip strength; LBM: lean body mass; TBF: total body fat; Sy.x: standard error about linear regression; $\mathrm{V}_{\mathrm{E}}$ : minute ventilation; $\mathrm{VCO}_{2}$ : carbon dioxide production; $\mathrm{VO}_{2}$ : oxygen uptake; ISWD: incremental shuttle walk distance; and MWV: maximum walking velocity. ${ }^{a}$ Model A included age, body mass, height and sex; model B included age, body mass, height, sex, and HGS; and model C included age, body mass, height, sex, LBM, and TBF. 'Use "mean" column for prediction of the expected values and "LLN" column for lower limit of normal. 'Sex: males $=1$; females $=0$. *Significant predictors $(p<0.05)$. 


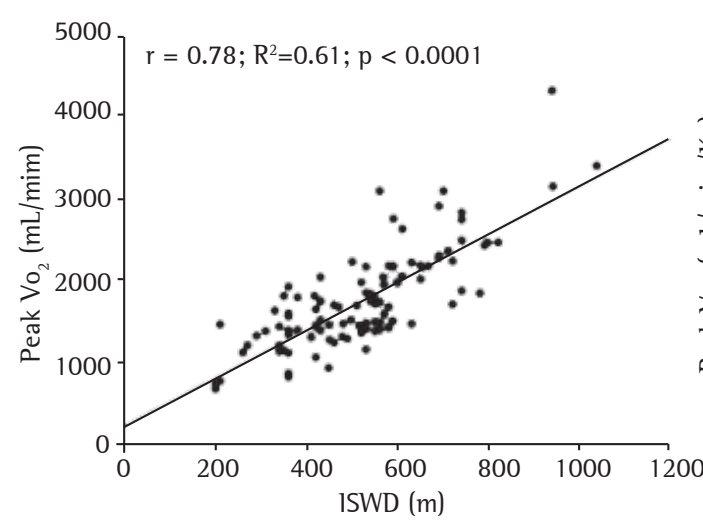

Equation: Peak $\mathrm{VO}_{2}=238.3-(2.9 \times 1 \mathrm{IWD})$

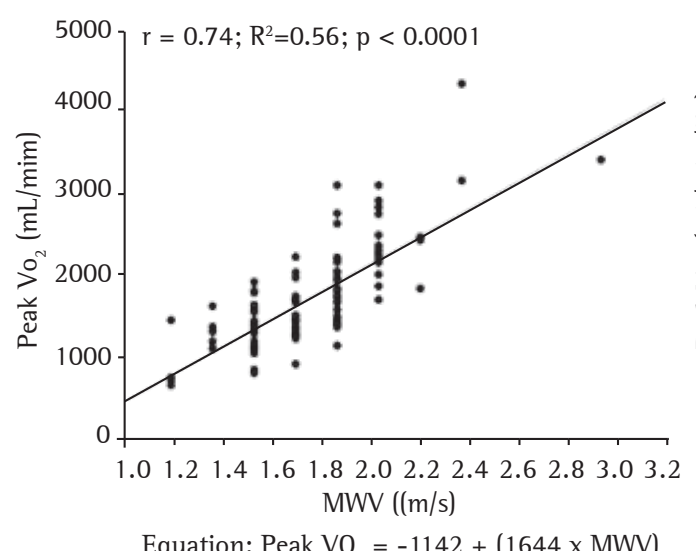

Equation: Peak $\mathrm{VO}_{2}=-1142+(1644 \times \mathrm{MWV})$

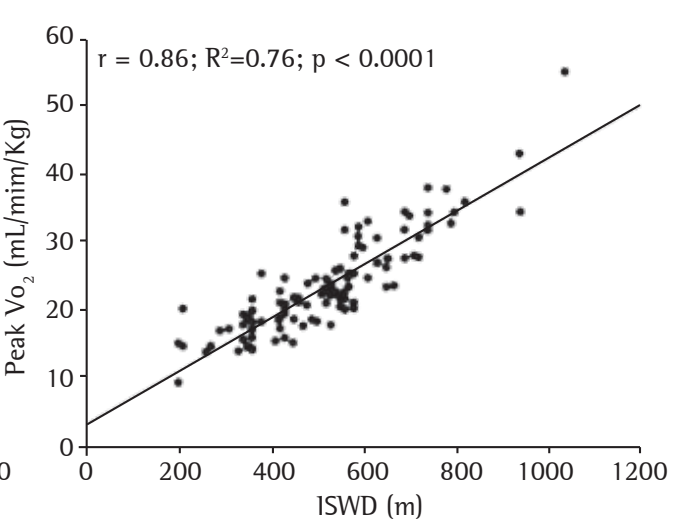

Equation: Peak $\mathrm{VO}_{2}=3.1+(0.038 \times 1 \mathrm{SWD})$

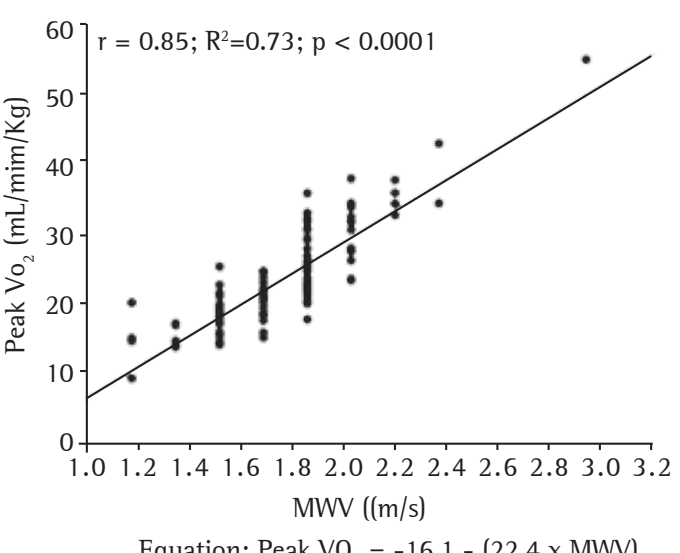

Equation: Peak $\mathrm{VO}_{2}=-16.1-(22.4 \times \mathrm{MWV})$

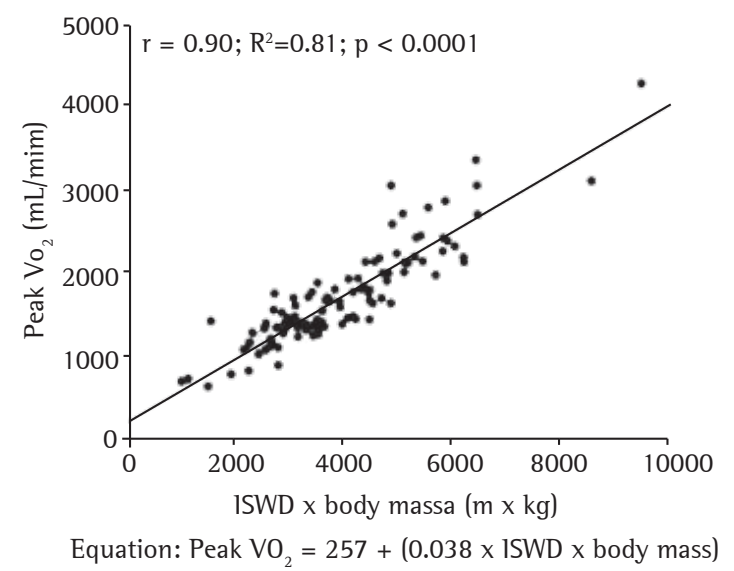

Figure 1 - Significant correlations between peak $\mathrm{VO}_{2}$ and incremental shuttle walk distance (ISWD), as well as between peak $\mathrm{VO}_{2}$ and maximal walking velocity (MWV), during the incremental shuttle walk test.

ISWD $\times$ body mass ranged from 0.75 to 0.90 . These values are similar to those described in the literature for the correlation between ISWD and peak $\mathrm{VO}_{2}$ obtained under laboratory conditions in patients with cardiopulmonary disease. Consistent correlations between peak $\mathrm{VO}_{2}$ and ISWD or between peak $\mathrm{VO}_{2}$ and $1 \mathrm{SWD} \times$ body mass obtained in CPET have been described in COPD patients (range, 0.73-0.88). ${ }^{(2,10,19,20)}$ Correlations of this magnitude have also been described during CPET in patients with idiopathic pulmonary fibrosis ${ }^{(21)}$ and in patients with heart disease. ${ }^{(22-24)}$ These 
results support the assertion that the ISWT is a suitable tool to assess the functional capacity of such patients. Our results indicate that the peak $\mathrm{VO}_{2}$ obtained during the ISWT might be adequately estimated by using ISWD, MWV, or body mass. In fact, léger \& Lambert ${ }^{(25)}$ reported similar results in the study in which they developed the precursor to the ISWT (the incremental shuttle run test). In that study, the peak $\mathrm{VO}_{2}$ of young adults was adequately predicted by the running speed, with a correlation of $r=0.84$. In a study conducted by Cooper, who used the 12-min run test, ${ }^{(26)}$ the 12 -min run distance was also the most important determinant of cardiorespiratory fitness in healthy young adults, a finding similar to those of the present study. Even in CPET, the work rate, or power, has been identified as the main determinant of peak $\mathrm{VO}_{2}{ }^{.27)}$ Because the ISWT is performed on a flat surface, the MWV ultimately represents the workload of the test.

Sex and age influenced the main variables obtained on the ISWT (peak $\mathrm{VO}_{2}$, ISWD, and MWV). Several studies have reported that peak $\mathrm{VO}_{2}$ suffers a decline with advancing age and is lower in women, ${ }^{(28,29)}$ even when allometric correction is used. ${ }^{(30)}$ In the present study, $\mathrm{R}^{2}$ values for ISWD, adjusted for age, body mass, height, and sex, ranged from $15 \%$ to $22 \%$, which are higher than those reported in the study conducted by Jürgensen et al., ${ }^{(7)}$ in which those attributes explained 50\% of the ISWD variability. This difference might be attributable to the characteristics of the sample evaluated in that study, which included individuals with mild hypertension and smokers, whereas only healthy participants were included in the present study. We found that body composition and HGS, although presenting consistent correlations with peak $\mathrm{VO}_{2}$, did not sufficiently increase the predictive power of the equations adjusted only for demographic and anthropometric attributes. Neder et al. ${ }^{(29)}$ reported similar results in a study involving CPET on a cycle ergometer. In that study, the residuals of the equations involving muscle strength and body composition were narrowed, although the $\mathrm{R}^{2}$ was not sufficiently increased. ${ }^{(29)}$ Our results suggest that equations including age, sex, body mass, and height are useful because those variables are very simple to obtain and provide $R^{2}$ values similar to those of models with variables that are more difficult to obtain, such as body composition and muscle function (Table 2).

Various cardiovascular and ventilatory variables were determined in the present study by a combination of age, sex, height, and body mass ( $R^{2}$ ranging from 0.54 to 0.65$)$. Our results are similar to those described by Neder et al.,(29) who reported that several cardiovascular and ventilatory variables might be determined by the combination of age, sex, height, and body mass, with an $\mathrm{R}^{2}$ ranging from 0.102 to 0.691 .

The use of a gas analysis system did not result in worse performance during the third ISWT in the present study, given that the results of the second and third 1SWTs were not significantly different and exhibited excellent reliability. Our results differ from those described by Singh et al., ${ }^{(10)}$ who reported a shorter ISWD with the use of a telemetric gas analysis system. This discrepancy might be explained primarily by the total weight of the equipment we used, which was lower than the $4.1 \mathrm{~kg}$ of that used by Singh et al. ${ }^{(10)} \mathrm{In}$ addition, those authors ${ }^{(10)}$ evaluated COPD patients, whereas our study involved only healthy participants. Our results show that, despite some minor discomfort related to the use of a face mask, the use of the equipment had no impact on the ISWD.

Our study has limitations that should be considered. The main limitation was that we did not perform CPET. However, comparing our results with those expected for CPET on a cycle ergometer derived from a randomized study, ${ }^{(29)}$ the measured peak $\mathrm{VO}_{2}$ during the 1SWT was significantly higher than the expected values for CPET on a cycle ergometer $(1,760 \pm 608$ $\mathrm{mL} / \mathrm{min}$ vs. $1,568 \pm 438 \mathrm{~mL} / \mathrm{min}, \mathrm{p}=0.017$ ). Regarding CPET on a treadmill, when we compare our results with those found in another study conducted in Brazil, ${ }^{(28)}$ albeit qualitatively, the peak $\mathrm{VO}_{2}$ achieved during the ISWT corresponded to $80.6-108.2 \%$ of the peak $\mathrm{VO}_{2}$ expected in that study. Another limitation was the convenience sampling technique that we used, which might have resulted in overestimation of the normal physiological responses. However, we took care to include only healthy individuals who were not involved in sports or vigorous physical activity. We believe that this minimized the bias of the sampling technique used.

Our results provide reference values for ISWD and physiological responses to the ISWT, which can be properly estimated by determining simple 
demographic and anthropometric characteristics in healthy adults $\geq 40$ years of age. The inclusion of body composition and muscle function data improved the power of those estimations only slightly. Therefore, the 1SWT could be used in assessing physical fitness in the general adult population and in designing individualized walking programs. Because the pace set in the initial levels of the ISWT is too slow for healthy individuals, future studies should investigate ways in which the original protocol can be adapted for use in this population.

\section{Acknowledgments}

The authors would like to thank the Faculty of the American Thoracic Society and the Methods in Epidemiologic, Clinical and Operations Research (MECOR) program, especially Dr. William M. Vollmer, for their support in the statistical analysis during the First MECOR Global Course, held in Nairobi, Kenya, in 2011.

\section{References}

1. Singh SJ, Morgan MD, Scott S, Walters D, Hardman AE. Development of a shuttle walking test of disability in patients with chronic airways obstruction. Thorax. 1992;47(12):1019-24.

2. Onorati P, Antonucci R, Valli G, Berton E, De Marco F, Serra $P$, et al. Non-invasive evaluation of gas exchange during a shuttle walking test vs. a 6-min walking test to assess exercise tolerance in COPD patients. Eur $\mathrm{J}$ Appl Physiol. 2003;89(3-4):331-6.

3. Singh SJ. Chapter 7. Walking for the assessment of patients with chronic obstructive pulmonary disease. Eur Respir Mon. 2007;40(1):148-64.

4. Ringbaek T, Martinez G, Brøndum E, Thøgersen J, Morgan M, Lange P. Shuttle walking test as predictor of survival in chronic obstructive pulmonary disease patients enrolled in a rehabilitation program. J Cardiopulm Rehabil Prev. 2010;30(6):409-14.

5. Dourado VZ, Banov MC, Marino MC, de Souza VL, Antunes LC, McBurnie MA. A simple approach to assess VT during a field walk test. Int J Sports Med. 2010;31(10):698-703.

6. Tully MA, Cupples ME, Hart ND, McEneny J, McGlade $\mathrm{KJ}$, Chan WS, et al. Randomised controlled trial of home-based walking programmes at and below current recommended levels of exercise in sedentary adults. J Epidemiol Community Health. 2007;61(9):778-83.

7. Jürgensen SP, Antunes LC, Tanni SE, Banov MC, Lucheta PA, Bucceroni AF, et al. The incremental shuttle walk test in older Brazilian adults. Respiration. 2011;81(3):223-8.

8. Dourado VZ, Vidotto MC, Guerra RL. Reference equations for the performance of healthy adults on field walking tests. J Bras Pneumol. 2011;37(5):607-14.

9. Probst VS, Hernandes NA, Teixeira DC, Felcar JM, Mesquita RB, Gonçalves CG, et al. Reference values for the incremental shuttle walking test. Respir Med. 2012;106(2):243-8.

10. Singh SJ, Morgan MD, Hardman AE, Rowe C, Bardsley PA. Comparison of oxygen uptake during a conventional treadmill test and the shuttle walking test in chronic airflow limitation. Eur Respir J. 1994;7(11):2016-20.

11. Luxton N, Alison JA, Wu J, Mackey MG. Relationship between field walking tests and incremental cycle ergometry in COPD. Respirology. 2008;13(6):856-62.

12. Win T, Jackson A, Groves AM, Sharples LD, Charman SC, Laroche CM. Comparison of shuttle walk with measured peak oxygen consumption in patients with operable lung cancer. Thorax. 2006;61(1):57-60.

13. Sociedade Brasileira de Pneumologia e Tisiologia. Diretrizes para Testes de Função Pulmonar. J Pneumol. 2002;28(Suppl. 3):S1-S238.

14. American College of Sports Medicine Position Stand. The recommended quantity and quality of exercise for developing and maintaining cardiorespiratory and muscular fitness, and flexibility in healthy adults. Med Sci Sports Exerc. 1998;30(6):975-91.

15. Boneva-Asiova Z, Boyanov MA. Body composition analysis by leg-to-leg bioelectrical impedance and dual-energy $\mathrm{X}$-ray absorptiometry in non-obese and obese individuals. Diabetes Obes Metab. 2008;10(11):1012-8.

16. Oppliger RA, Case HS, Horswill CA, Landry GL, Shelter AC. American College of Sports Medicine position stand. Weight loss in wrestlers. Med Sci Sports Exerc. 1996;28(6):ix-xii.

17. Neder JA, Nery LE, editors. Fisiologia clínica do exercício: teoria e prática. São Paulo: Artes Médicas; 2003.

18. Mathiowetz V, Kashman N, Volland G, Weber K, Dowe M, Rogers S. Grip and pinch strength: normative data for adults. Arch Phys Med Rehabil. 1985;66(2):69-74.

19. Turner SE, Eastwood PR, Cecins NM, Hillman DR, Jenkins SC. Physiologic responses to incremental and self-paced exercise in COPD: a comparison of three tests. Chest. 2004;126(3):766-73.

20. Arnardóttir RH, Emtner M, Hedenström H, Larsson K, Boman G. Peak exercise capacity estimated from incremental shuttle walking test in patients with COPD: a methodological study. Respir Res. 2006;7:127.

21. Moloney ED, Clayton N, Mukherjee DK, Gallagher CG, Egan JJ. The shuttle walk exercise test in idiopathic pulmonary fibrosis. Respir Med. 2003;97(6):682-7.

22. Morales FJ, Montemayor T, Martinez A. Shuttle versus six-minute walk test in the prediction of outcome in chronic heart failure. Int J Cardiol. 2000;76(2-3):101-5.

23. Green DJ, Watts K, Rankin S, Wong P, O'Driscoll JG. A comparison of the shuttle and 6 minute walking tests with measured peak oxygen consumption in patients with heart failure. J Sci Med Sport. 2001;4(3):292-300.

24. Lewis ME, Newall C, Townend JN, Hill SL, Bonser RS. Incremental shuttle walk test in the assessment of patients for heart transplantation. Heart. 2001;86(2):183-7.

25. Léger LA, Lambert J. A maximal multistage 20-m shuttle run test to predict V02 max. Eur J Appl Physiol Occup Physiol. 1982;49(1):1-12.

26. Cooper KH. A means of assessing maximal oxygen intake. Correlation between field and treadmill testing. JAMA. 1968;203(3):201-4.

27. American College of Sports Medicine, Thompson WR, Gordon NF, Pescatello LS, editors. ACSM's guidelines of exercise testing and prescription. Philadelphia: Lippincott Williams \& Wilkins; 2009.

28. Herdy $\mathrm{AH}$, Uhlendorf D. Reference values for cardiopulmonary exercise testing for sedentary and active men and women. Arq Bras Cardiol. 2011;96(1):54-9. 
Reference values for the incremental shuttle walk test in healthy subjects:

from the walk distance to physiological responses

29. Neder JA, Nery LE, Castelo A, Andreoni S, Lerario MC Sachs A, et al. Prediction of metabolic and cardiopulmonary responses to maximum cycle ergometry: a randomised study. Eur Respir J. 1999;14(6):1304-13.
30. Neder JA, Nery LE, Silva AC, Andreoni S, Whipp BJ. Maximal aerobic power and leg muscle mass and strength related to age in non-athletic males and females. Eur J Appl Physiol Occup Physiol. 1999;79(6):522-30.

\section{Sobre os autores}

Victor Zuniga Dourado

Adjunct Professor. Universidade Federal de São Paulo - UNIFESP, Federal University of São Paulo - Baixada Santista Campus, Santos, Brazil.

\section{Ricardo Luís Fernandes Guerra}

Adjunct Professor. Universidade Federal de São Paulo - UNIFESP, Federal University of São Paulo - Baixada Santista Campus, Santos, Brazil.

\section{Suzana Erico Tanni}

Pulmonologist. Universidade Estadual Paulista - UNESP, São Paulo State University - Botucatu School of Medicine, Botucatu, Brazil.

\section{Letícia Cláudia de Oliveira Antunes}

Professor. Marechal Rondon College, São Manuel, Brazil. Physical Therapist. Universidade Estadual Paulista - UNESP, São Paulo State University - Botucatu School of Medicine Hospital das Clínicas, Botucatu, Brazil.

\section{Irma Godoy}

Full Professor. Universidade Estadual Paulista - UNESP, São Paulo State University - Botucatu School of Medicine, Botucatu, Brazil. 